\title{
Erratum to: Fibroblast viability and phenotypic changes within glycated stiffened three-dimensional collagen matrices
}

Vanesa Vicens-Zygmunt ${ }^{1,2^{*}}$, Susanna Estany², Adai Colom ${ }^{3,8}$, Ana Montes-Worboys ${ }^{2}$, Carlos Machahua ${ }^{2}$, Andrea Juliana Sanabria ${ }^{4}$, Roger Llatjos ${ }^{2,5}$, Ignacio Escobar ${ }^{6}$, Frederic Manresa ${ }^{1,2}$, Jordi Dorca ${ }^{1,2}$, Daniel Navajas ${ }^{3,7}$, Jordi Alcaraz ${ }^{3,7 \dagger}$ and Maria Molina-Molina ${ }^{1,2,7 \dagger}$

\section{Erratum}

After publication of the original article [1] it came to the publisher's attention that there was a formatting error in Table 1 and the text ' $5 \mathrm{mM}$ and $15 \mathrm{mM}$ ' had been inserted on the wrong line. This has now been corrected in the original article.

\begin{abstract}
Author details
'Department of Pneumology, Unit of Interstitial Lung Diseases, University Hospital of Bellvitge, Barcelona, Spain. ${ }^{2}$ Pneumology Research Group, IDIBELL, University of Barcelona, Barcelona, Spain. ${ }^{3}$ Unit of Biophysics and Bioengineering, University of Barcelona, Barcelona, Spain. ${ }^{4}$ Department of Preventive Medicine, University Hospital of Bellvitge, Barcelona, Spain. ${ }^{5}$ Department of Pathology, University Hospital of Bellvitge, Barcelona, Spain. ${ }^{6}$ Department of Thoracic Surgery, University Hospital of Bellvitge, Barcelona, Spain. ${ }^{7}$ Research Network in Respiratory Diseases (Centro de Investigación Biomédica en Red (CIBER) de Enfermedades Respiratorias), ISCIII, Barcelona, Spain. ${ }^{8}$ Department of Biochemistry, University of Geneva, Science II, Geneva, Switzerland
\end{abstract}

Received: 24 September 2015 Accepted: 24 September 2015 Published online: 02 November 2015

\section{Reference}

1. Vicens-Zygmunt V, Estany S, Colom A, Montes-Worboys A, Machahua C, Sanabria AJ, et al. Fibroblast viability and phenotypic changes within glycated stiffened three-dimensional collagen matrices. Respir Res. 2015;16:82.

\footnotetext{
*Correspondence: vvicens@hotmail.com

${ }^{\dagger}$ Equal contributors

'Department of Pneumology, Unit of Interstitial Lung Diseases, University Hospital of Bellvitge, Barcelona, Spain

${ }^{2}$ Pneumology Research Group, IDIBELL, University of Barcelona, Barcelona, Spain

Full list of author information is available at the end of the article
}

\section{Submit your next manuscript to BioMed Central and take full advantage of:}

- Convenient online submission

- Thorough peer review

- No space constraints or color figure charges

- Immediate publication on acceptance

- Inclusion in PubMed, CAS, Scopus and Google Scholar

- Research which is freely available for redistribution

(c) Vicens-Zygmunt et al. 2015 Open Access This article is distributed under the terms of the Creative Commons Attribution 